\title{
CULTURA DEL TERRITORIO
}

\author{
MARÍA ZÚÑIGA \\ Colegio de Geógrafos \\ JORGE OLCINA \\ Asociación Española de Geografía
}

La cultura es la expresión máxima del grado de civilización de una sociedad. Son múltiples las manifestaciones de cultura que un grupo humano que ha alcanzado un grado elevado de civilización puede presentar. Generalmente asociamos cultura a expresión artística, literaria o musical. Desde la Geografía creemos que cultura se vincula también a un modo de actuar basado en los principios y valores de la sociedad, a una actitud en las relaciones del ser humano con su medio y a una manera ética de afrontar las cuestiones que plantea nuestra vida en la superficie terrestre.

La Geografía, disciplina básica en el eje de conocimientos principales del ser humano, es -o debe ser- ciencia del buen hacer territorial. Es uno de sus principios fundacionales que debe cultivar con fuerza para mantener su esencia epistemológica.

Esto lo vieron claro un grupo de académicos de la Geografía que hace más de una década promovieron un manifiesto en defensa de una Nueva Cultura del Territorio (1). Este fue, y sigue siendo, un documento de referencia para la práctica de una cultura ética, responsable, sensata y sostenible en los procesos territoriales.

Fue en el año 2006. Se vivía entonces en la euforia de la burbuja inmobiliaria: un momento de la historia contemporánea española, excelente para la economía o, mejor dicho, para algunas economías, pero nefasto para el territorio. La ocupación de espacios y su transformación para uso urbano o para el trazado de infraestructuras, en ocasiones en áreas protegidas o con riesgo natural, fue intensa. Asistíamos a una verdadera depredación del suelo en algunas regiones españolas, y todo bajo el lema del supuesto progreso colectivo y la necesidad de 
crear puestos de trabajo. Cuando se produjo el estallido de esta burbuja, a partir de 2008, se evidenció la fragilidad de este modelo de crecimiento económico y se experimentó la crudeza de sus efectos. Aún hoy no han sido del todo superados, especialmente en lo relativo a las desigualdades sociales agravadas en esos años de recesión. Sin olvidar un ingrediente más que tuvo al territorio, al suelo, como actor principal y proliferó en algunas administraciones regionales y locales de entonces: el despilfarro y la corrupción asociada. Se daban, pues, todos los ingredientes para que el territorio se encontrara en una situación de grave vulnerabilidad como no había alcanzado nunca antes.

De ahí el valor del Manifiesto para una Nueva Cultura del Territorio (NCT) que el Colegio de Geógrafos y la Asociación Española de Geografía (AGE), con un núcleo promotor de geógrafos y geógrafas redactaron e hicieron público para expresar la voz de la Geografía en esta cuestión. Se recibieron más de 400 adhesiones (2) desde ámbitos disciplinares diversos relacionados con la planificación y gestión territorial y urbana y con el medio ambiente. Desde ambas entidades se considera que la elaboración de este documento, con las adendas de actualización posteriores en 2009 y 2018, es una de las acciones institucionales más relevantes de la geografía española, en las últimas décadas. Es además, uno de los motivos de orgullo de pertenencia a una disciplina y una profesión puesto que refleja el compromiso social que desde ambas se tiene como parte fundamental de nuestras funciones. El carácter de denuncia pública del manifiesto NCT respecto a unos hechos que nunca debieron producirse, unido a la presentación de propuestas concretas para mejorar el orden de cosas existente, reafirma el carácter de la Geografía como ciencia del territorio y profesión al servicio del mismo.

El manifiesto original NCT (3) se escribió en el convencimiento de que "el buen gobierno del territorio, de la ciudad y del campo es responsabilidad de todos y un tema político de primer orden". En esta línea, se proponía el propio concepto de NCT y los 10 objetivos que se asocian al mismo:

1. El territorio es un bien no renovable, esencial y limitado.

2. El territorio es una realidad compleja y frágil.

3. El territorio contiene valores ecológicos, culturales y patrimoniales que no pueden reducirse al precio del suelo.

4. Un territorio bien gestionado constituye un activo económico de primer orden.

5. El planeamiento territorial y urbanístico es un instrumento esencial para la actuación de los poderes públicos. 
6. El planeamiento municipal debe tener como principal objetivo facilitar el acceso a la vivienda.

7. El planeamiento territorial debe proveer acuerdos básicos sobre el trazado de las infraestructuras, el desarrollo de los asentamientos y el sistema de los espacios abiertos.

8. El Gobierno central y las Cortes Generales del Estado no pueden desentenderse del territorio.

9. En un mundo crecientemente integrado la gestión del territorio debe atender también a los compromisos de solidaridad y responsabilidad global.

10. El impulso de los valores de sostenibilidad ambiental, eficiencia económica y equidad social requiere de una nueva cultura del territorio.

El manifiesto de la Nueva Cultura del Territorio ha conocido dos actualizaciones en forma de adendas. La primera en 2009 (4), en plena crisis económica, que destacaba el papel del territorio como oportunidad para salir de la misma apostando por su consideración "como el marco de vida construido entre todos" y no como mero recurso. Se señalaba el protagonismo que deberían tomar los poderes públicos como agentes principales en la elaboración de políticas territoriales. Además, se indicaba la necesidad de regenerar la acción política en la política territorial que había derivado en muchos casos, durante los años del boom inmobiliario, en acciones de ilegalidad y corrupción, como se ha comprobado a posteriori. Se redactó también, otro manifiesto asociado al concepto NCT por la preservación y gestión de los espacios costeros, que surgió a raíz del anuncio de modificación de la Ley de Costas anterior, que databa de 1988 (5).

La segunda adenda (6), presentada en sociedad en 2018, recogiendo una serie de indicaciones a considerar en la gestión territorial en relación con nuevos procesos socio-económicos y aspectos legales y administrativos, surgidos en los últimos años en nuestro país (cambio climático, riesgos, despoblación, problema del alquiler de vivienda, indicadores de sostenibilidad, infraestructura verde) que es preciso incorporar en la ordenación del territorio.

La adenda de 2018, concluía señalando que "los nuevos territorios del cambio global que se están gestando en los últimos años, deben incluir la equidad y la justicia ambiental, la igualdad de género, la erradicación de la pobreza, la activación del patrimonio territorial y la transparencia en los procesos administrativos como objetivos fundamentales de su planificación y gestión. En ese sentido, no puede olvidarse tampoco que nuestro país tiene un compromiso ineludible con el cumplimiento de los 17 Objetivos de Desarrollo Sostenible (horizonte 2030) 
de las Naciones Unidas, cuyos principios y concreción tienen plasmación directa en el espacio geográfico, pudiéndose cumplir sólo con medidas de planificación racional y sostenible del territorio".

Para impulsar las ideas del Manifiesto de la Nueva Cultura del Territorio y promover su recuerdo periódicamente, el Colegio de Geógrafos y la AGE decidieron poner en marcha la celebración del Premio NCT (7) que se convoca de manera bienal. Este premio tiene la "finalidad de fomentar una cultura del territorio mediante el reconocimiento de personas, entidades e instituciones que hayan contribuido de forma relevante al impulso de una ordenación y gestión del territorio fundamentada en valores de sostenibilidad ambiental, eficiencia económica y equidad social".

Han sido seis las ediciones que ha habido hasta ahora. Se han concedido a las siguientes entidades y personas (indicando la justificación dada por el jurado):

- Primera edición (2009): Concedido a D. Andrés Rábago «El Roto», por "su trayectoria como profesional de la ilustración y el soporte crítico a la Cultura del Territorio".

- Segunda edición (2011): Concedido a Fundación César Manrique, por “su defensa de los valores naturales y culturales de la isla de Lanzarote, especialmente en los modelos de buenas prácticas en la gestión sostenible de sus usos turísticos".

- Tercera edición (2013): Concedido a Dr. D. Ángel Cabo Alonso, sirvió como "homenaje a una larga y fructifera trayectoria dedicada a la investigación y difusión del territorio de Castilla y León".

- Cuarta edición (2015): Concedido a Ecologistas en Acción, como “confederación de grupos que entiende que los problemas medioambientales tienen su origen en un modelo de producción y consumo cada vez más globalizado, del que derivan también otros problemas sociales, y que hay que transformar si se quiere evitar la crisis ecológica".

- Quinta edición (2017): Concedido a Dra. Da. Josefina Gómez Mendoza, "en reconocimiento a una trayectoria defendiendo los valores de respeto por el territorio, la sostenibilidad y una visión integral de los procesos y elementos que se dan sobre el mismo".

- Sexta edición (2019): En este momento el premio se renovó estableciendo dos categorías: divulgación y gestión; y además se abrió la presentación de candidaturas a todos los miembros del Colegio de Geógrafos y de la 
AGE. El premio en la categoría de divulgación de los valores del territorio fue concedido al escritor Julio Llamazares, "en cuya obra, el paisaje es un eje de descripción del relato de hechos y una seña de identidad de los personajes protagonistas".

En la categoría de gestión del territorio el premio fue concedido al Observatorio del Paisaje de Cataluña, "como centro de pensamiento y de acción sobre el paisaje que desde 2004 se ha convertido en el punto de encuentro entre la Administración, las universidades, los colectivos profesionales y el conjunto de la sociedad en todo lo relacionado con la gestión y la cultura del paisaje".

El territorio es espacio, es historia y es cultura. Es una manifestación del nivel de desarrollo de una sociedad, pero es, sobre todo, expresión de la cultura de la población que habita ese espacio. Las sociedades con una cultura del territorio avanzada respetan los valores naturales, patrimoniales, históricos, sociales y económicos de sus territorios: los ordenan y planifican desde el respeto, la sostenibilidad, la igualdad y la transparencia, asumiendo la responsabilidad de actuar conforme a valores éticamente correctos. Sociedades, como la española, con una cultura territorial con amplio margen de mejora, manifiestan deficiencias en la manera de entender la relación entre las personas y su medio. De ahí la actualidad y la necesidad de poner en práctica los principios defendidos en el Manifiesto por una Nueva Cultura del Territorio, único camino correcto para planificar y gestionar la complejidad espacial propia del mundo actual.

Enlaces de referencia:

1. https://www.geografos.org/manifiesto-por-una-nueva-cultura-del-territo$\underline{\text { rio/ }}$

2. https://www.geografos.org/wp-content/uploads/2013/07/interes_nuevacultura_adhesiones-por-una-nueva-cultura-del-territorio-junio_-20111. pdf

3. https://www.geografos.org/wp-content/uploads/2013/07/interes_nuevacultura manifiesto-por-una-nueva-cultura-del-territorio-d5.pdfS

4. http://www.age-geografia.es/site/wp-content/uploads/2018/06/Adenda-2009_MANIFIESTO_NuevaCulturadelTerritorio.pdf

5. https://www.geografos.org/manifiesto-por-la-preservacion-y-gestion-delos-espacios-costeros/ 
6. https://www.age-geografia.es/site/manifiesto-nueva-cultura-del-territorio/

7. https://www.geografos.org/premio-nueva-cultura-del-territorio/

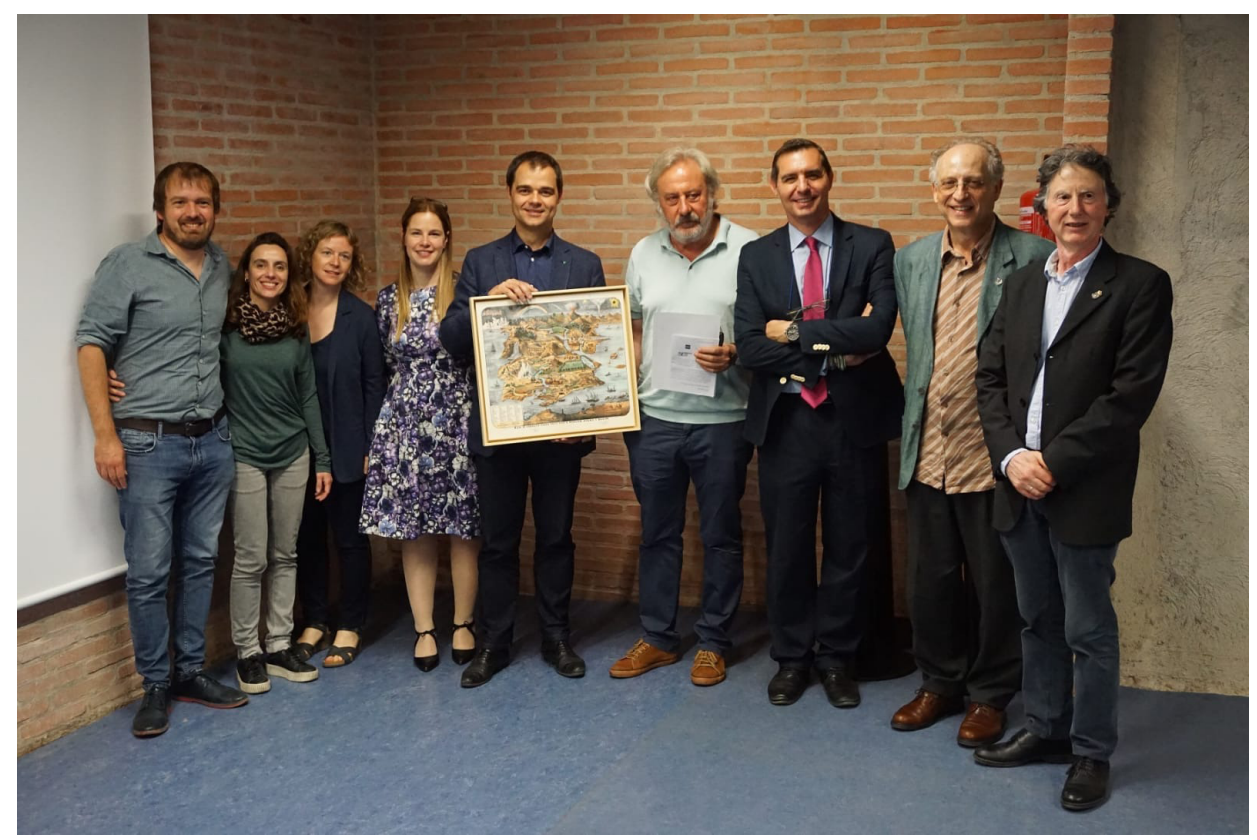

Organización, premiados y presentadores.

Fotografia: AGE y Colegio de Geógrafos

Imágenes en CANAL UNED:

https://canal.uned.es/video/5cf7aca4a3eeb0d4078b4567 


\section{NUEVA CULTURA DEL TERRITORIO

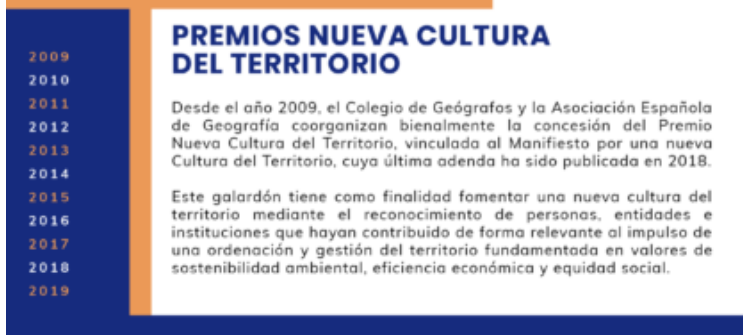

\section{PREMIO NCT}

2009 Concedido a D. Andrés Róbago *El Rotow, por su trayectoria como profesional de la ilustración y el soporte crítico a la Cultura del Territorio.

\section{PREMIO NCT}

201.1. Concedido a Fundación César Manrique, su defensa de los valores naturales y culturales de la isla de Lanzarote. especialmente en los modelos de buenas prócticas en la gestión sostenible de sus usos turísticos.

\section{PREMIO NCT}

201.3 Concedido a Dr. D. Ángel Cabo Alonso, sirvió en homenaje a una largua y fructifera trayectoria dedicada a la investigación y difusión del territorio de Castilla y León.

\section{PREMIO NCT}

2015 Concedido a Ecologistas en Acción, como confederación de grupos que entiende que los problemas medioambientales tienen su origen en un modelo de producción y consumo codo vez más globalizodo. del que derivan tambien atros problemas socioles, y

\section{PREMIO NCT}

2017 Concedido a Dra. D: Josefina Gómez Mendoza, en reconocimiento a una trayectoria defendiendo los valores de respeto por el termitorio. la sostenibilidady una vision integral de

\section{PREMIO NCT}

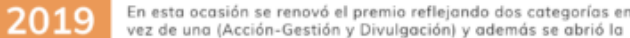
presentación de candidaturas a todos los miembros del Colegio de Geógrafos y de la AGE.

Premio en la categoría de divulgación de los volores del territorio concedido al escritor Julio Llamazares, en cuya obro, el paisaje es un eje de descripción del relato de hechos y una seña de identidad de los personajes protagonistas.

Premio en la categoría de gestión del territorio concedido al Observatorio del Paisaje de Cataluño, como centro de pensamiento y de acción sobre el paisaje que desde 2004 se ha convertido en el punto de encuentro entre la Administración, las universidades. los colectivos profesionaies y el conjunto de la sociedad en todo lo relacionado con la gestión y la cultura de paisaje.

\section{0años20razones}




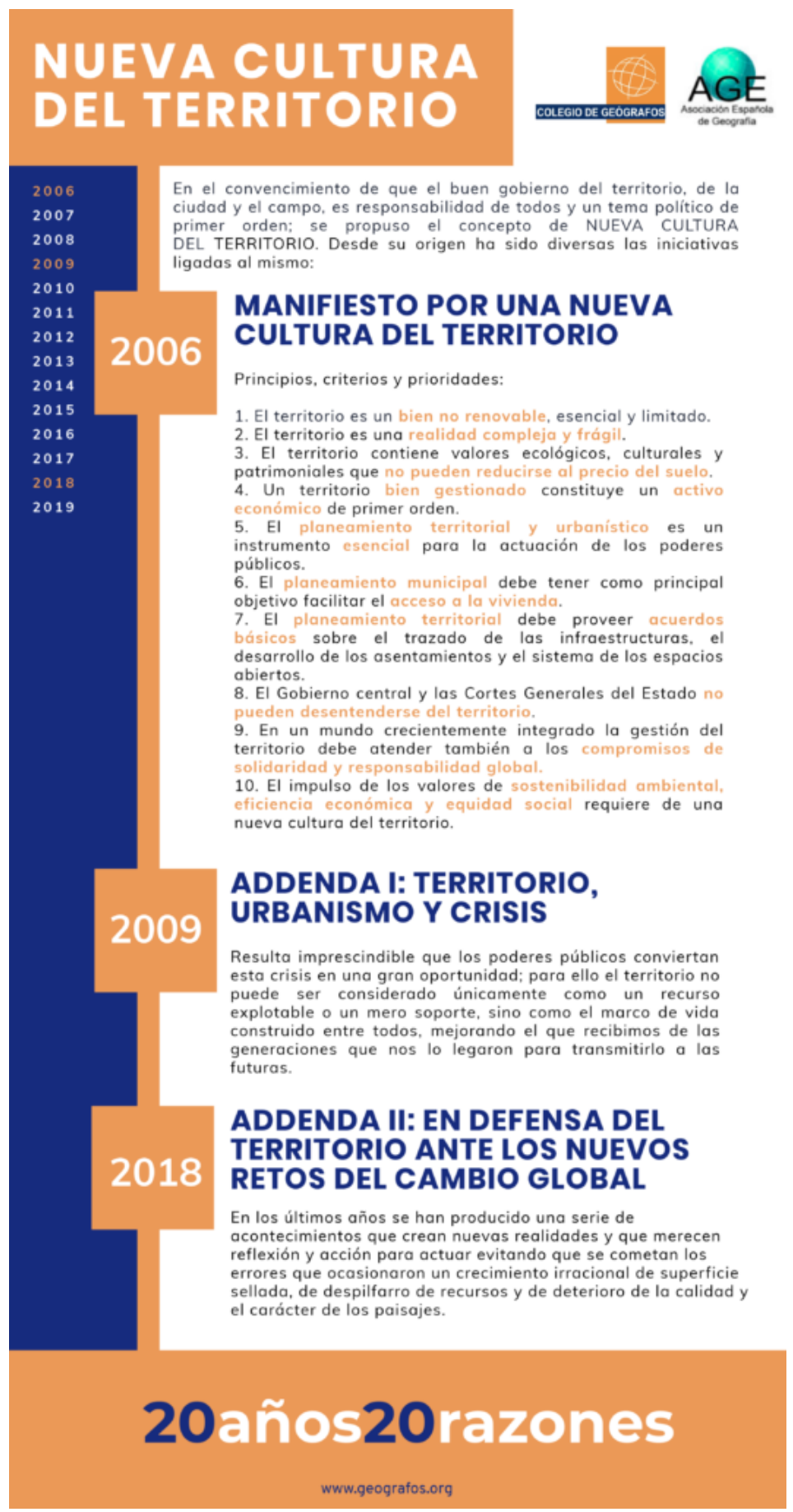

Polígonos. Revista de Geografía, 31 (2019); 37-44 